\title{
Mars satellite flies into hunt for lost Beagle 2
}

Declan Butler, Paris

Since Christmas Day, British mission controllers have listened in vain for a signal from their Beagle 2 Mars lander. Now the orbiter that carried the probe to the red planet is about to join in the search.

On 4 January, the Mars Express craft, operated by the European Space Agency (ESA), will begin sweeping the surface of Mars for radio signals from Beagle 2. The mother ship represents the best chance of finding out whether the lander survived its descent to the martian surface.

Beagle 2 was jettisoned by Mars Express on 19 December, a camera on board the ESA craft photographing the pocket-watch-shaped lander falling away on the final 3 million kilometres of its 400-million-km journey. It should have entered the martian atmosphere at around $20,000 \mathrm{~km}$ per hour at $2.45 \mathrm{am}$ GMT on 25 December, before landing in the crater of Isidis Planitia about six minutes later, slowed to some $60 \mathrm{~km}$ per hour by parachutes and cushioned by airbags.

Just under three hours after that, mission controllers had hoped that Beagle 2's calling sign - a nine-note tune composed by the pop band Blur — would be picked up by NASA's Mars Odyssey craft, which has been orbiting the red planet since 2001. Over the days that followed, Mars Odyssey repeatedly tried and failed to make contact with the lander. The 76-metre Lovell radio telescope at the Jodrell Bank observatory in Cheshire, UK, and a 45-metre dish at Stanford University in California also drew a blank.

For the team behind Beagle 2, led by Colin
Pillinger of the Open University in Milton Keynes, Beagle 2's silence has been frustrating. "This is a bit disappointing, but it's not the end of the world," says Pillinger. Mars Express and Beagle 2 were designed to talk to each other, so the addition of the mother ship to the search party should give the best chance of detecting the lander.

Mars Express itself slipped into orbit in the middle of Christmas morning - an The Beagle is stranded: Colin Pillinger has tried in vain to contact his impressive result for Mars lander since its scheduled touchdown on Christmas Day. ESA's first planetary mission. This weekend, mission controllers will fire the orbiter's engine for three minutes to nudge it from equatorial orbit into its final polar orbit, where it can begin operating on 4 January.

This new orbit will allow frequent passes over Beagle 2's landing area. At around the same time, the lander, which currently only broadcasts at set times, is programmed to switch to an emergency mode in which it will broadcast continuously during daylight hours.

Despite Beagle 2's high media profile - a product of Pillinger's gift for publicity (see Nature 423, 476;2003) - Mars Express is the main part of ESA's mission. It carries a high-resolution camera to map the planet, a near-infrared spectrometer to assess surface mineralogy, radar to search for subsurface water down to a depth of $5 \mathrm{~km}$, and instruments to study the planet's upper atmosphere and its interaction with the solar wind.

While the search for Beagle 2 continues, two NASA exploration rovers are also on their way to Mars (see Nature 423, 477; 2003). The first, Spirit, is also due to land on 4 January; the second, Opportunity, will touch down on 25 January.

www.beagle2.com

www.esa.int/mars

\section{Beef blockade greets first mad cow in United States}

Rex Dalton and Erika Check

For the United States Department of Agriculture (USDA), it was about worst the Christmas present imaginable: the country's first case of mad cow disease. Nations around the world responded by banning the import of US beef.

The diagnosis of bovine spongiform encephalopathy (BSE) - in a 'downer' cow, unable to walk yet still sent for slaughter and human consumption - was confirmed on 25 December. Two days later, the USDA tentatively traced the animal to a herd imported from Alberta, Canada, which announced North America's first 'homegrown' case of BSE last May (see Nature $423,467 ; 2003)$. A previous Canadian case, in 1993, occurred in a cow imported from Britain.

The new US case is from a farm in Mabton, Washington, about 200 kilometres southeast of Seattle. Efforts are being made to recall potentially contaminated meat products. Even though the cow may not have been infected in the United States, the case has raised questions about the adequacy of measures designed to keep BSE out of the US cattle herd - and to protect people from infection with the brain-wasting disease. In particular, scientists are calling for an expansion of the BSE-testing programme for slaughtered cattle.

The animal was probably infected by eating feed contaminated with the 'prion' proteins that are thought to cause the disease. Both the United States and Canada have banned the feeding to cattle of meat and bone meal from sheep and cows, although the meal can still be fed to other livestock. Experience in Britain, which introduced a similar ban in 1988 , suggests that such bans are difficult to enforce unless meat and bone meal from ruminants is completely excluded from animal feed.

Experts also say that too few cattle are being tested for BSE in the United States to be sure that infected animals are not entering the human food supply. There is no routine testing for the 30 -million-plus cattle slaughtered each year - and only about $10 \%$ of the 200,000 or so downer cattle slaughtered in 2003 were tested, even though an inability to walk is a known symptom of BSE. "We should be testing more animals," argues Frederick Murphy, a veterinary scientist at the University of California, Davis.

The case is also likely to lead to a revival of attempts to exclude all downer cows from the human food supply. Such efforts have previously been defeated after lobbying from agricultural interests. 